\title{
The Role of Responsive Library Makerspaces in Supporting Informal Learning in the Digital Humanities
}

\author{
Karen Miller, Erik Champion, Lise Summers, Artur Lugmayr, Marie Clarke
}

Many people involved in the digital humanities share an interest in building and making things, often using digital tools and technologies and, as often as not, developing the tools themselves. Makerspaces are ideal for supporting and generating excitement around such digital humanities projects. Bethany Nowviskie aptly describes makerspaces as "skunkworks", semi-independent, research-oriented spaces that offer "ways forward not only for the works of innovative digital scholarship, but for the technical and social frameworks necessary to support and sustain them" [1]. Using an inquiry based, constructivist learning approach, makerspaces provide a fun, accessible and informal means of building confidence and digital literacy, the key to a digital humanities education [2], as well as a means of incubating and prototyping ideas which can develop into research projects [3]. The unique contribution of makerspaces is in providing a creative and safe space to develop ideas, share materials and equipment, play and experiment [4]. In contrast to digital humanities centres, which are more formal environments supported by partnerships and formal collaborations with "specific desired outcomes or the pursuit of articulated research questions", makerspaces are "intended to be a creative, open environment in which researchers can experiment with new ideas in a communal atmosphere... the emphasis is on individual growth through praxis: the creation of new products or ideas through prototyping: and community learning." [5]

The nature of the relationship between the makerspace and the digital humanities community can be understood through the idea of the makerspace as a "liminal space". A liminal space can be described as "betwixt and between", located at the limits of existing structures and with a creative potential that can be attributed to the "suspension of the usual constraints of organizational life - routines, rules, boundaries and the expectations of others" [6] As Thomassen suggests:

Thinking with liminality serves to conceptualize moments where the relationship between structure and agency is not easily resolved .... the very distinction between structure and agency ceases to make sense; and yet, in the hyper-reality of liminality, structuration and meaning-formation take form. [7]

The freedom from structure that liminality presents sparks creativity and innovation, and presents opportunities for "transformation and empowerment" that arises out of the tension between "formal institutional strategies and less formal experiences" [8]. Liminal spaces, then, are characterized by an inherent contradiction between structure and agency that gives rise to creativity. As creative spaces that sit on the edge, makerspaces are liminal, characterized by tension between their informal nature, and the more formal structural requirements that enable creative processes to be nurtured. This has been our experience with the Curtin Library Makerspace, 
which is located at the intersection of the Library and the wider university community, hosted and resourced by the library, yet shaped by its community, the users and stakeholders.

We thread ideas around the relationship between makerspaces and digital humanities together using the concept of liminal space and identifying the apparent contradictions between structure and agency, formality and informality. Using the Curtin Library Makerspace as a case study, it focuses on several of the digital humanities activities and projects that the five authors, academics and librarians, have been involved with. The digital humanities community at Curtin University is a fluid network of connections of academics and students with intersecting interests and collaborations working across a range of schools within the humanities faculty and wider university community. The chapter demonstrates how the Makerspace is becoming a cornerstone for this dispersed Curtin digital humanities community, providing an informal creative space and associated activities that support their work. It then looks at how the Makerspace supports digital humanities pedagogy through an inquiry based learning approach, looking in particular at its contribution in supporting the curriculum in a VisMedia course using design thinking; and an Information Studies course using hands-on learning activities. The chapter also considers the issues involved in the Makerspace as an equal partner in digital humanities projects by reflecting on the experience of two interrelated events, the 'GLAMVR' symposium, and the hackathon-style 'Cultural Makathon', as well as a longer-term software development project using the Kinect body-tracking camera. Each of these exchanges highlight the challenge of negotiating the complex relationship between an informal, creative and unstructured approach to exploring the digital humanities and the need for structural and formal elements to guide, maintain and support the further development of the projects, events and activities that arise from it.

\section{The makerspace as a creative and informal learning environment}

The Curtin Library Makerspace was established in 2015 as an informal learning environment to encourage cross-disciplinary, inquiry-based learning through maker activities and to foster the development of digital fluency. As a space designed for sharing tools, equipment, skills and knowledge, it hosts a range of different activities to encourage an informal and creative learning environment. However, some structure to ensure safe and secure administration of the space, as well as provide guidance to learn skills and work toward outcomes, is required. Achieving the right balance is the challenge.

Starting small, and evolving gradually, the Makerspace has developed in response to the needs and interests of makers within the Curtin community, with digital humanities emerging as a key area of practice. Run by a part-time coordinator and supported by library staff and volunteers, the Makerspace consists of a small work area with stored equipment and materials such as electronics, 3D printing and scanning, virtual reality equipment and arts and craft materials. Over a short time it has created a vibrant maker community exploring many different creative activities 
ranging from building robots, spinning wool, or creating interactive artworks. Through these activities the Makerspace encourages a creative and playful approach to learning through making based on self-directed learning, experimentation, exploration and collaboration [9].

To ensure that Makerspace retains its inherent qualities as an informal learning environment, the structural elements are intentionally kept minimal. The Library has been gradually developing policies and procedures around access and safe use and administration of the space and equipment, as needs arise. Although it is currently located in a small space (with plans to expand) the Makerspace is mobile and often uses other learning environments and locations outside the library, by setting up a "pop-up" makerspace. It frequently participates in campus wide or community events such as festivals, open days, orientation and outreach activities, which provide informal maker activities while enjoying the benefits of infrastructural support by way of funding, marketing and publicity, resources and volunteer help. As well as informal drop-in sessions, the makerspace also facilitates more structured workshops, facilitated by individuals and groups within the maker community, designed to foster the development of skills such as working with Arduinos, Robotics and Virtual Reality.

One of the challenges of the Makerspace is to achieve a balance between providing enough structure and guidance while allowing space for independent problem solving. This is highlighted in our experience with a community event the Makerspace ran in 2015 called 'Light Makers at the Library', which was held to celebrate National Science Week. The Makerspace facilitated hands-on workshops, including creating LED-illuminated origami flowers, inventing with Makey Makeys, exploring sewable electronics, experimenting with light painting using mobile apps, creating hologram viewers and lighting text and images with paper circuitry. An introductory Arduino workshop encouraged participants to design and code a visual LED animation displayed on a coloured 'pixel shield'. The 'Bright bunnies' workshop involved soldering a circuit board, and then sewing a felt bunny to enclose the circuit board, an LED, and a magnet switch [10]. The different activities varied in terms of their level of structure but in general aimed to teaching basic skills, techniques and knowledge. In the Bright Bunnies workshop, for example, soldering the circuit board was highly structured, with the facilitators providing detailed instruction and wellsupervised guidance to teach this complex process in a safe manner. Once participants had completed the circuitry, they were provided with pre-cut felt templates to sew and embellish. It was a surprise and a delight to see many participants go off-script by 'hacking' the felt bunny template to create other creatures instead, such as monsters or dinosaurs.

The experience, and others like it, has taught us that a balance needs to be sought between a certain level of structure and guidance required to teach complex skills and the need to retain a level of informality to allow scope for exploration and creative expression. While each situation is different, constrained by factors such as time or the need to master certain techniques, workshops that are open-ended and more focused on the process rather than a particular outcome, such as the Ready 
Set Design! model from the Smithsonian Museum [11], are beneficial in encouraging inventiveness and experimentation. Developing an inquiry based learning approach, which underpins the general philosophy of our Makerspace, is a key factor in achieving this.

\section{The Makerspace as a support for inquiry based learning}

An inquiry based learning approach is central to the ethos of any makerspace, making it particularly significant for digital humanities pedagogy. The Curtin Library Makerspace has contributed to inquiry based learning in several formal teaching contexts. In the VisMedia course, the Makerspace provided facilities and support for students using a design thinking model to develop ideas for visualisation projects, while Information Studies students were able to explore maker technologies as hands-on engaging learning activities within their regular workshops. The examples demonstrate how makerspaces contribute to positive learning outcomes by enabling informal approaches to inquiry based learning to be integrated into more structured teaching situations.

Makerspaces are increasingly significant for digital humanities pedagogy. They foster "an inquiry-based approach to learning that values experimentation, tinkering, and play as important means of discovery" and "promote an engagement with new forms of critical thinking through the process of making" [12]. An inquiry based learning approach to making emphasizes "creative, improvisational problem solving", centred on the "open-ended design and construction of objects or installations, generally using both high- and low-tech tools". At the heart of this "tinkering" process, students develop a personally meaningful idea, get stuck but persist to make breakthroughs and find solutions to problems which arise, not through being assigned, but through the learners initial "exploratory engagement with the materials, people, practices, and ideas available in the tinkering setting" [13]. By collaborating with teaching faculty to use this approach to engage with the curriculum, makerspaces offer opportunities to support class projects or activities and showcasing or exhibiting student work $[14,15]$ as our experience demonstrates.

The Curtin Library Makerspace has made an important contribution to curriculum delivery in providing infrastructural support to a new Curtin University study program which commenced in 2015, Visualisation and Interactive Media (VisMedia) [16]. The course aims at a cross-disciplinary investigation of latest media technologies - in particular visualization - at the intersection of content production, technology development, and business. The goal is to create a community of students with various backgrounds, develop product ideas, prototype these, test ideas, and create business plans. The teaching modality, which uses a design thinking approach, is similar to the process of start-up companies or creative projects to cope with consumer driven service demands. Having to comply with certain teaching requirements has resulted in a modified design thinking model [17] to fit within a rigid curriculum and pre-defined teaching modalities, as well as existing learning spaces and infrastructures, by introducing a more practical teaching schedule and utilising the Curtin Library Makerspace. 
The Makerspace provided students with a creative space, technologies to enable the development of prototypes, and assistance with conducting brainstorming sessions. The phases of defining, ideation, prototyping, and user testing of the design thinking cycle have been extremely successful within the Makerspace. The space was especially suited for collaboration across disciplines and supported the pedagogical efforts of creative thinking and playful approaches towards the creation of new digital services. Some of the outputs of the VisMedia course, such as a virtual tour of the Curtin Library using panoramic 360 degree photography, and creating a data visualisation using Library entry data, which were presented at the course's show case event are examples of VisMedia projects involving student and Library collaboration.

The Makerspace has also been involved in a less formal way with Information Studies students who are training to be information professionals involved in digital literacy education in libraries, archives and records institutions. We introduced maker activities into the weekly workshops to create engaging learning activities that stimulated thinking around various concepts and practical ideas, such as building Lego models to represent conceptual frameworks, experimenting with LittleBits to explore different learning styles, or using Makey Makeys to create prototypes of an interactive learning resource in response to a scenario-based problem. These activities were not assessed as a core component of the curriculum, which in effect added an element of informality and fun to the sessions and arguably created a more effective learning experience. Introducing maker activities in this way helped to develop student's digital fluency skills, exposing them to new technologies and ideas to better equip them in their future professional roles.

These examples demonstrate how makerspaces can contribute to formal teaching activities by providing suitable spaces, equipment and facilitation expertise. Importantly, it also opens up an avenue for informal learning within what is, of necessity, a structured curriculum. This is beneficial for achieving the desired learning outcomes, and helping students achieve the digital fluency they need as creative graduates who are well equipped to face the challenges of the future with well developed critical thinking and problem solving skills. Our experiences have shown that an inquiry based learning approach can work well within the structured curriculum, not only developing student skills in digital humanities work but producing particular outputs as prototypes, which have the potential to be developed further into digital humanities projects.

\section{The Makerspace as a partner in research projects and outputs}

While makerspaces within libraries are primarily a service, providing facilities, resources and equipment as well as assistance and expertise, they can also play a strong defining role in digital humanities projects. The Curtin Library Makerspace has been involved in several interrelated digital humanities events and projects, including a one-day 'GLAMVR' symposium, a Cultural Makathon, and a particular software development project using Kinect body tracking camera. Using these 
examples, we highlight some of the elements that underpin the process of project development, included the importance of knowledge sharing, developing ideas into prototypes, and creating finished outputs. Some of the relevant issues worth considering are the preservation of project research data and outputs, the sustainability of projects, and the need to develop the research capabilities of the Makerspace.

Networking and knowledge sharing is an essential element of fostering the work of digital humanities, and one in which the Library Makerspace has played a central role. With funding from a Humanities faculty strategic grant, staff, students and invited speakers congregated at our university's visualisation centre, the HIVE, to give presentations about their digital humanities research on a range of subjects including 3D modelling, linked open data, archives, preservation, visualisation, makerspaces, cinematic biofeedback, and multimodal panoramic environments of cultural heritage content [19]. The symposium also featured workshops that focussed on connecting archival material to a game environment [18] and phonebased augmented reality [20] using the Unity game engine, which gave valuable 'under the hood' insights into the processes involved in project development. Along with presenters and invited speakers, the symposium drew interest from academics, university and state-based librarians and other heritage content providers or designers. It offered the opportunity to explain how both MR/AR (mixed reality/augmented reality) and VR (virtual reality) were leaping ahead in power, flexibility and accessibility, hindered more by a lack of suitable examples than by the technology itself, and to help support new ways of integrating technology with traditional archival and bibliographical data. It was beneficial in building relationships within the Curtin community and networks with industry, important components of building a digital humanities community of practice. Another important outcome was being able to continue to forge connections with practical ways to develop projects, which was our aim in hosting a 'Cultural Makathon' as a follow up event.

The Cultural Makathon was an opportunity for the Makerspace to support the process of experimenting with programming and data and developing ideas and prototypes. We modeled the event on the 'Hackathon', where coders and software designers get together to solve a problem or meet a challenge in a limited time frame. Inspired by hackathons that have been established to promote use of data and assist cultural institutions [21] the Makathon aimed to encourage digital scholars, particularly in the humanities, to test hypotheses and examine ways to interrogate cultural data. Invited representatives from cultural heritage institutions acted as 'data mentors' to introduce the data sets and catalogue sites and provide support to participants. The participating teams utilised open data provided by Australia's cultural heritage institutions to develop prototypes including a VR experience, an iOS app and a musical composition derived from data, while a fourth team worked with materials in the Makerspace to produce physical art works from which they created digital components [22]. The Library played an important role in the Makathon, not only by providing the space and organisational support, but also 
by participating in the Makathon, as former or existing library staff members were well represented on the teams.

As exemplified by the University of Virginia's Scholar's Lab [23] makerspaces can help incubate and prototype ideas which can then be developed further as research projects and incorporated into the digital humanities [3]. However, longer term development of digital humanities projects requires more sustained support. Some of the relevant issues were highlighted during a project initiated by two of the authors, one interested in 3D cultural heritage [24] the other interested in digital literacy and public engagement with library resources. We wanted to create a way to access $2 \mathrm{D}$ and $3 \mathrm{D}$ library resources as a more interactive and creative alternative to the conventional means of a desktop environment, using the Kinect v2, a bodytracking camera. Acting as mentors and clients' in a project-based software engineering course, we worked with computer science students to successfully create a prototype of a GUI (Graphical User Interface) that could be used in the design of interactive activities that would allow 'players' to customize movements and gestures to control game engines like Minecraft. [25] With the project still a work in progress, the next step is to develop the product further through user testing, assess its suitability for use in classrooms and public spaces such as libraries and museums, and investigate the potential of Minecraft for library-related interactions. However, sustaining momentum in projects like these is a real challenge, due to frequent changes in student cohorts or even the software and hardware.

These three examples highlight several issues around preservation, sustainability and research capacity that have implications for development of digital humanities projects into finished outputs. Being able to continue to work on projects, even if the original developers are no longer involved, relies on an infrastructure that can maintain, preserve, and make available and accessible the components, versions, iterations, research data and notes as well as the outputs from the projects. Digital humanities projects are typically as much about the digital tools as the content they interact with. Continued development relies on evaluating tools, equipment and prototypes through user experience testing and other practice based research methods.

There is potential for the Makerspace to be equal partners in, or lead, library-related research projects. "Critical making" provides a useful "mode of materially productive engagement that is intended to bridge the gap between creative physical and conceptual exploration" with the goal of "using material production-making things-as part of an explicit practice of concept elaboration". [26]. The research capacity of the makerspace could be developed by testing digital humanity project outputs, investigating the process of making, and evaluating the efficacy of the makerspace's programs and services. This relies not only on individuals with an interest in pursuing such ideas, but also funding resources, which in turn requires partnerships, and collaborations with different creative areas within the university and wider industry sector. As Miriam Posner and others point out, the library needs to move beyond providing a support service to being equal partners in digital 
humanities projects to achieve this $[27,28]$. An infrastructure of some sort is required to be able to provide the necessary support.

Based on our experience, a suitable infrastructure would be one that can retain the informal, playful approach of the Makerspace while at the same time developing some aspects of a more formally constructed DH centre to support collaborations. Of the three digital humanities organizational models that Burrows and Verhoeven describe - the service model, lab model and network model - the latter one reflects our approach most closely. The network model:

recognises that there are likely to be multiple units across a campus with expertise, resources and activities relevant to the digital humanities, and focuses instead on providing coordination across them and helping them to pool their efforts. This might be done formally through a central hub with various nodes, or through more informal mechanisms to encourage cooperation and collaboration between units. [29]

This model is in line with advocating a community of practice: as Williams and Folkman argue, "[m]aking maker communities of practice fits into any library's vision and practice"[30].

\section{Conclusion}

Our interactions between the Makerspace and some of the digital humanities work occurring within Curtin University have shown that while a loose, informal approach to the Makerspace's role fosters creativity and innovation, an infrastructure is nonetheless important for maintaining and developing longer-term projects and creating finished outputs. A successful community of practice relies on achieving a balance between informal, loose connections based on mutual interests and relationship building, and more structured elements that enable the connections within the community of practice to be made. A tiered structure, guided by representatives from the digital humanities community would allow for both informal and formal practices to occur.

The first tier would focus on the Makerspace as a service, providing space and equipment as well as facilitating the development of digital skills. It would seek to preserve its informal nature enabling the freedom to tinker, explore and experiment, yet containing it with procedures and guidelines for the administration of the space and strategic frameworks to articulate the Makerspace's vision, aims and objectives. A second tier would support incorporating maker activities into the curriculum structure in collaboration with teaching academics and potentially community based designers or makers using an inquiry based learning approach. A third tier would aim to support and partner in research projects by collaborating on funding opportunities to develop projects, sponsoring visiting scholars or resident makers, and building the evaluative and pedagogical research capabilities of the Makerspace. 
As a liminal space existing "betwixt and between" the library and the digital humanities community, the Curtin Library Makerspace has nurtured a creative learning environment that encourages hands-on, inquiry based learning. We have demonstrated the different ways in which the contradiction between structure and agency, formality and informality, is manifest. We have highlighted the informal nature of the Makerspace as a driving force in fostering digital humanities work, while the structural elements act as necessary support. The challenge is in achieving the right balance between these two contradictory elements in order to successfully develop the Makerspace in ways that continue to progress a positive partnership between the library and the digital humanities to further this important work.

\section{References}

[1] B. Nowviskie, Skunks in the Library: A path to production for scholarly R\&D. Journal of Library Administration 53 (1) (2013) 53-66 (p. 53). doi.org/10.1080/01930826.2013.756698

[2] D. M. Rieder, J. Elam-Handloff, Makerspaces: Curatorial statement, Digital Pedagogy in the Humanities, MLA Commons.

<https://digitalpedagogy.mla.hcommons.org/keywords/makerspaces/> (accessed 15.03.17)

[3] J. Vinopal, M. McCormick, Supporting digital scholarship in research libraries: Scalability and Sustainability, Journal of Library Administration 53 (1) (2013) 27-42. doi.org/10.1080/01930826.2013.756689

[4] R. Wexelbaum, Assessing Safe Spaces for Digital Scholarship in the Library, LIBRES: Library and Information Science Research, 26 (1) (2016) 14-30.

<http://www.libres-ejournal.info/2385/>

[5] T.C. Bergstrom, Digital Scholarship Centres: converging space and expertise, in A. MacKenzie, L. Martin (eds), Developing Digital Scholarship: Emerging practices in academic libraries. Neal Schuman, Chicago, 2016, (Chapter 6). (p. 107)

[6] J. Swan, H. Scarbrough, M. Ziebro, Liminal roles as a source of creative agency in management: The case of knowledge-sharing communities, Human Relations, 69 (3) (2016) 781-811 (p.782). https://doi.org/10.1177/0018726715599585

[7] B. Thomassen, Liminality and the modern: living through the in-between, Farnham, VT Ashgate, 2014. (p.1)

[8] V. Rutherford, I. Pickup, Negotiating Liminality in Higher Education: Formal and Informal Dimensions of the Student Experience as Facilitators of Quality, 703-723, in A. Curaj et al. (eds.), The European Higher Education Area, Cham Springer, 2015. DOI 10.1007/978-3-319-20877-0_44 (p.703).

[9] Curtin Makers, <https://maker.library.curtin.edu.au/> (accessed 15.03.17)

[10] K. Miller, Exploring light during National Science Week <https://maker.library.curtin.edu.au/2015/11/15/light-makers-2/>, 2015 (accessed 15.03.17)

[11] Ready, Set, Design! <https://www.cooperhewitt.org/2011/09/09/ready-setdesign/> (accessed 29.05.17)

[12] D. M. Rieder, J. Elam-Handloff, Makerspaces: Curatorial statement, Digital Pedagogy in the Humanities, MLA Commons. 
<https://digitalpedagogy.mla.hcommons.org/keywords/makerspaces/> (accessed 16.07.17)

[13] B. Bevan, J.P. Gutwill, M. Petrich, K. Wilkinson, Learning through STEM-Rich tinkering: Findings from a jointly negotiated research project taken up in practice. Science Education, 99 (1) (2015) 98-120. (p. 99) https://doi.org/10.1002/sce.21151 [14] S.D. Shapiro, Engaging a Wider Community: The academic library as a center for creativity, discovery, and collaboration. New Review of Academic Librarianship, 22 (1) (2016) 24-42. (pp. 31-32), https://doi.org/10.1080/13614533.2015.1087412 [15 ] I. Fourie, A. Meyer, What to make of makerspaces. Library Hi Tech, 33(4), (2015). 519-525.

[16] Visualisation and Interactive Media (VisMedia). <http://www.curtin.edu.au/vismedia> (accessed 15.03.17)

[17] A. Lugmayr, B. Stockleben, Y. Zou, S. Anzenhofer, M. Jalonen. Applying 'Design Thinking' in the context of media management education. Multimedia Tools and Applications 71 (1) (2014) 119-157. doi:10.1007/s11042-013-1361-8 [18] \#GLAMVR16 26.08.2016 <http://slides.com/erikchampion/glamvr16-26-082016\#/> (accessed 15.03.17)

[19] Michael Wiebrand's webpage. Morfaine. <http://www.morfaine.com/> (accessed 15.03.17)

[20] Dominic Manley's webpage <http://dominicmanley.com/>. (accessed 15.03.17)

[21] Culture Hack <http://culturehack.org.uk/about/> 2nd Swiss Open Cultural Data Hackathon http://make.opendata.ch/wiki/event:2016-07 (accessed 15.03.17).

[22] M. Clarke, Hacking and making with cultural data <https://maker.library.curtin.edu.au/2016/12/22/hacking-making-cultural-data/> (accessed 15.03.17)

[23] Scholar's Lab, University of Victoria (http://scholarslab.org/)

[24] E. Champion, L. Qiang, D. Lacet, A. Dekker. 3D in-world telepresence with camera-tracked gestural interaction. 14th EUROGRAPHICS Workshop on Graphics and Cultural Heritage, 5-7 October 2016, Genoa, Italy. Short paper.

http://dx.doi.org/10.2312/gch.20161394

[25] K. Miller, Creating a GUI for the Kinect v 2

https://maker.library.curtin.edu.au/2016/08/02/creating-a-gui-for-kinect-v-2/ (accessed 29.05.17)

[26] M. Ratto, Critical Making: Conceptual and Material Studies in Technology and Social Life. The Information Society, 27 (4) (2011) 252-260. (p. 252)

https://doi.org/10.1080/01972243.2011.583819

[27] M. Posner. No Half Measures: Overcoming Common Challenges to Doing Digital Humanities in the Library. Journal of Library Administration, 53 (1) (2013) 43-52. https://doi.org/10.1080/01930826.2013.756694

[28] S. Varner, P. Hswe. (2016). Digital Humanities in Libraries. American Libraries, 47 (1/2) 36-41. https://americanlibrariesmagazine.org/2016/01/04/special-reportdigital-humanities-libraries/ (accessed 16.07.17)

[29] T. Burrows and D. Verhoeven. Libraries and the digital humanities: partnership, collaboration and shared agendas. VALA Conference. Melbourne, 9-11 February, 2016. (p. 3) https://www.vala.org.au/direct-download/vala2016- 
proceedings/vala2016-papers/592-vala2016-session-9-burrows-paper/file (accessed 29.05.17)

[30] B.F. Williams, M. Folkman, Librarians as Makers. Journal of Library Administration, 57 (1) (2017) 17-35.

https://doi.org/10.1080/01930826.2016.1215676 (p. 21) 